F. Perkins, A. Klimczuk, Area Agencies on Aging, [in:] D. Gu, M.E. Dupre (eds.), Encyclopedia of

Gerontology and Population Aging, Springer, Cham 2020, pp. 1-5, https://doi.org/10.1007/978-3-31969892-2 219-1.

\title{
Area Agencies on Aging
}

Fatima Perkins

Western Reserve Area Agency on Aging, Cleveland, OH, USA

Andrzej Klimczuk

SGH Warsaw School of Economics, Warsaw, Poland

\section{Definition}

An area agency on aging (AAA) is a public or private nonprofit organization designated by the state to address the needs and concerns of all older persons at the regional and local levels in the United States (Administration for Community Living (ACL) 2019). AAAs have a successful history of developing, coordinating, and implementing comprehensive networks of services and programs that enrich communities and the lives of older adults. AAAs were established through a provision of the Older Americans Act (OAA 1965), which was signed into law by

President Lyndon B. Johnson. Specifically, AAAs were created with the 1973 reauthorization of the OAA. AAAs create the infrastructure to execute comprehensive longterm support services that ensure the independence of older adults.

\section{Overview}

Globally and nationally, demographic shifts reveal a significant increase in the older population. In the near future, worldwide, older adults will outnumber children (Vespa 2019). Though most communities have some resources to address the potential needs of this growing population, the United States will need to ensure continuous funding to support the network of organizations, including AAAs.

Nearly 45 percent of older Americans report their health status as being "very good to excellent." The paradox is that 77 percent of persons aged 65 or above have two chronic conditions, such as arthritis, diabetes, high cholesterol, and/or hypertension (AoA 2018). Due to progressive healthcare practices and other positive societal variables, the average individual will live well into their late 70s. With the increase in longevity, many older adults will experience a myriad of challenges and opportunities. In order to experience the optimal quality of life, the nation will need to keep at least 11 considerations at the forefront: (1) access to food resources that support nutritional needs; (2) case management to assist the most vulnerable with accessing care; (3) community and virtual focal points to facilitate coordination of services; (4) 
F. Perkins, A. Klimczuk, Area Agencies on Aging, [in:] D. Gu, M.E. Dupre (eds.), Encyclopedia of

Gerontology and Population Aging, Springer, Cham 2020, pp. 1-5, https://doi.org/10.1007/978-3-31969892-2 219-1.

support employment opportunities; (5) improve healthcare and health literacy; (6) provide information, assistance, and referral; (7) foster lifelong learning opportunities that engage and empower; (8) provide resources to support caregivers; (9) provide safe universally designed and accessible housing; (10) improve technology adoption and procurement of devices; and (11) ensure transportation to health-related appointments as well as social activities.

Each State Unit on Aging (SUA) determines the number of AAAs to be established and corresponding regions. The AAAs network consists of 622 entities that work with a combined 20,000 local service providers to provide community-based services. Though AAAs have mandates to focus on particular priorities, each AAA is guided by the needs of its region with a distinctive approach to resolve those needs. AAAs serve older adults with the greatest need, particularly low-income, weakened individuals, residents of rural areas, and minority individuals (Ujvari et al. 2019).

\section{History}

AAAs were established as a critical component of the OAA (1965) in response to having an adequate and comprehensive network throughout the United States to address the needs of older adults. The goal of the OAA is "to provide assistance in the development of new or improved programs to help older persons through grants to the states for community planning and services and training and project grants, and to establish within the Department of Health, Education, and Welfare an operating agency to be designated as the "Administration on Aging'." AAAs are at the core of the Aging Network, ensuring that the tenants of the OAA are being implemented for the empowerment of older adults.

\section{Structure of Area Agencies on Aging}

The year 1965 was a tumultuous time for the United States. The time was highlighted with remarkable events such as the Civil Rights Movement and the escalation of the Vietnam War. The time was also backdropped with popular invents that would define the era, such as the birth of the Pillsbury Doughboy; the debut of Green Acres, a popular sitcom; and Muhammad Ali's first-round one-minute knockout of Sonny Liston. Amidst these happenings, the life expectancy for the average older adult was approximately 70 years of age. Lyndon B. Johnson, President, and the 89th United States Congress recognized that not all Americans would have the opportunity to "age gracefully" because there were not enough social services to support successful aging. Also, the phenomenon of ageism was being acknowledged as a norm. Understanding that the nation needed to ensure that all older adults had the opportunity to experience a healthy, engaged, and adequately funded retirement, the OAA, which includes the 
F. Perkins, A. Klimczuk, Area Agencies on Aging, [in:] D. Gu, M.E. Dupre (eds.), Encyclopedia of

Gerontology and Population Aging, Springer, Cham 2020, pp. 1-5, https://doi.org/10.1007/978-3-31969892-2 219-1.

authorization of AAAs, was established.

The OAA is reauthorized every 10 years, giving the public an opportunity to recommend changes based on the emerging needs of the older adult population. With the 1973 reauthorization of the OAA, AAAs were created. Nationally, there are 56 SUAs and 622 AAAs. Based on a data-driven approach, SUAs establish the local AAAs and corresponding service areas that are referred to as the planning and service area (PSA). A PSA is defined as a geographical area of more than 100,000 people with a high percentage of individuals who are aged 60 and older.

In order to be designated as an AAA to coordinate a PSA, an entity must meet one of these criteria: (1) an existing organization which can meet the state requirements for an AAA; (2) a municipal, county, government council, or regional planning commission can be designated by an elected official as an AAA; and (3) public or nonprofit organization located in the PSA that can meet the state requirements for an AAA. Moreover, the Eldercare Locator, provided by the US Administration on Aging (AoA), has a website and toll-free number of connecting older people and caregivers with needed services in the requested area (Earnest 2017).

According to the National Association of AAAs (n4a), governance structure also varies for the 622 AAAs (n4a 2017): 39 percent are independent private nonprofits; 28 percent are part of a council of government or regional planning and development; 25 percent are part of a county government; 5 percent other; and 2 percent are part of a city government. The size of a PSA may vary. Most AAAs are serving several communities/counties; some AAAs such as Wisconsin serve 3 counties, while New York manages 59. AAAs work with local organizations for service delivery. Throughout the nation, AAAs partner with 20,000 service providers. Also, 244 Tribal Organizations (TOs) and 2 Native Hawaiian Organizations (NHOs) are authorized to serve older adults. The Aging Network is also supported by the talents and skills of over 200,000 volunteers.

\section{Planning and Preparing to Meet the Needs}

Each community is unique and requires assessment for AAAs to identify emerging issues and determine the strategies needed to address those issues. Therefore, every four years, AAAs welcome their communities to participate in forums to make recommendations. In conjunction with the SUAs, priorities and action steps are developed to ultimately improving the quality of life for older adults. Area plans for each AAAs can typically be found on organizational websites, for example, Aging \& Disability Services for Seattle \& King County (2020) and Senior Resources Agency on Aging (2020). AAAs and TOs strengthen the community's 
F. Perkins, A. Klimczuk, Area Agencies on Aging, [in:] D. Gu, M.E. Dupre (eds.), Encyclopedia of

Gerontology and Population Aging, Springer, Cham 2020, pp. 1-5, https://doi.org/10.1007/978-3-31969892-2 219-1.

capacity to help older adults remain healthy and independent. AAAs support the continuum of care by providing and/or contracting with service organizations to provide a multitude of programs and services: (1) case/care management; (2) elder rights, protection, elder abuse, and adult protective services; (3) employment; (4) family caregiver support; (5) health promotion; (6) home- and community-based services; (7) housing; (8) nutrition programs (on-site and home-delivered); and (9) transportation. With AAAs, critical needs can be addressed at a local level through a comprehensive approach ( $\mathrm{n} 4 \mathrm{a} 2019$ ). AAAs provide the support needed to sustain the service delivery infrastructure. AAAs partner with local service providers in their PSA to operationalize a continuum of long-term care services and supports.

\section{Prospects}

While the nation continues to grow old, AAAs will continue to evolve in response to serve the diverse older adult population. AAAs depend on OAA funding, which is allocated through SUAs. More funding needs to be allocated for research (Lytle 2019). The nation is accustomed to thoroughly reviewing the OAA every 10 years through a process of reauthorization, resulting in recommendations being made to improve policy that impacts targeted populations (e.g., OAA 2008, 2016; O’Shaughnessy 2012; Yao 2016).

In addition, every AAA must complete an area plan every 4 years that comprehensively addresses the needs and emerging issues of the older adults and persons with disabilities in their region. These are invaluable processes that often yield opportunities for research. However, most AAAs do not have the funds to explore, scale, replicate, and sustain these opportunities. Success in the arena of research will require AAAs and affiliates to be trained in basic research, including the evaluation and outcome-based methods. This type of training would help AAAs build the capacity to partner with research entities. The AAAs membership organization, National Association of AAAs (n4a), should consider providing leadership with this training need (n4a 2018).

Research areas that could be examined include (1) better understanding how diverse groups within the older adult population experience aging and identifying unique needs and strategies to address those needs; (2) exploring entrepreneurship and effective practices among AAAs; (3) interventions to reduce isolation and loneliness; (4) the dynamics of the intersection of policy and practice; (5) the impact and effectiveness of advocacy; and (6) core competencies for the AAA workforce. Moreover, in order to identify the concerns, AAAs need to foster partnerships with institutions that have the content knowledge and research experience (Earnest 
F. Perkins, A. Klimczuk, Area Agencies on Aging, [in:] D. Gu, M.E. Dupre (eds.), Encyclopedia of

Gerontology and Population Aging, Springer, Cham 2020, pp. 1-5, https://doi.org/10.1007/978-3-31969892-2 219-1.

2017). A significant research platform can be built by committing to an inclusive approach that includes consumers, service providers, funders, nonprofit organizations, educational institutions, healthcare organizations, and other stakeholders.

\section{Summary}

For the fiscal year 2019, the OAA received $\$ 2.06$ billion in funding. Though this figure is enormous compared with the 1965 appropriations, OAA funding has remained flat for approximately 18 years. The lack of funding for OAA subsequently impacts the capacity of AAAs to function (Ujvari et al. 2019).

By 2035 in the United States, older adults will outnumber children (Vespa 2019). By 2030, 73 million individuals will be aged 65 and older. This will account for one in five individuals being 65 and older. This demographic shift will continue in part due to the baby boomer population born between 1946 and 1964 (Ortman et al. 2014). In the presented context, AAAs will need substantial increases in funding to meet the needs of the older population adequately (Lytle 2019). With the majority of older adults preferring to stay in their communities versus institutionalization, AAAs will continue to be the backbone of support for planning, developing, coordinating, and delivering essential programs and services at the regional level.

Many of the challenges that precipitated the authorization of the OAA continue to exist and will continue to increase alongside the escalation of the older adult population. Older adults, communities, providers of service, and funders will need to design and support strategies in partnership with AAAs to achieve at least 11 aims: (1) advocate for adequate funding and other resources; (2) access employment opportunities and entrepreneurship; (3) civic engagement; (4) embrace technology as it advances; (5) encourage engagement; (6) intellectual stimulation; (7) manage a chronic disease; (8) media literacy; (9) prevent injuries such as falls; (10) reduce isolation and loneliness; and (11) support caregiving.

For decades, AAAs have been innovative by providing the coordination of service delivery coupled with innovative actions to sustain communities where older adults want to thrive and remain independent. In order to continue to achieve this success, AAAs will need to cultivate and sustain community partners with a shared vision of ensuring every older adult can age with dignity and optimal health.

\section{References}

Administration for Community Living (ACL) (2019) Area agencies on aging. 
F. Perkins, A. Klimczuk, Area Agencies on Aging, [in:] D. Gu, M.E. Dupre (eds.), Encyclopedia of Gerontology and Population Aging, Springer, Cham 2020, pp. 1-5, https://doi.org/10.1007/978-3-31969892-2 219-1.

https://acl.gov/programs/aging-and-disability-networks/area-agencies-aging. Accessed 03 Mar 2019

Administration on Aging (AoA), Administration for Community Living, U.S. Department of Health and Human Services) (2018) 2017 profile of older Americans. AoA, Washington, DC.

https://acl.gov/sites/default/files/Aging\%20and\%20Disability\%20in\%20America/20170ld erAmericansProfile.pdf. Accessed 01 Jun 2019

Aging \& Disability Services for Seattle \& King County (2020) Area Plan 2020-2023. https://www.agingkingcounty.org/data-reports/area-plan/. Accessed 8 Jul 2020 Earnest P (2017) Making connections: consumer needs in an aging America. Eldercare locator. n4a, Washington, DC. https://eldercare.acl.gov/Public/About/docs/n4a-datareport.pdf. Accessed on 22 Feb 2019

Lytle T (2019) Older Americans act needs money, support. AARP. 05 Apr 2019. https://www.aarp.org/politics-society/advocacy/info-2019/older-americans-actfunding.html. Accessed 15 Jun 2019

National Association of Area Agencies on Aging (n4a) (2017) Area agencies on aging: local leaders in aging and community living. $\mathrm{n} 4 \mathrm{a}$, Washington, DC. https://www.n4a.org/Files/LocalLeadersAAA2017.pdf. Accessed 03 Mar 2019

National Association of Area Agencies on Aging (n4a) (2018) Leadership in aging and community living: annual report 2017-2018. n4a, Washington, DC. https://www.n4a.org/Files/20172018\%20AR_final_web.pdf. Accessed 03 Mar 2019 National Association of Area Agencies on Aging (n4a) (2019). What the 116th congress needs to know about an aging America. n4a, Washington, DC. https://www. n4a.org/files/n4a_PolicyBrief_WhatThe116thCongress NeedsToKnow_Mar2019_FinalWeb.pdf. Accessed 29 Mar 2019

O'Shaughnessy C (2012) The basics: older Americans Act of 1965: programs and funding. National Health Policy Forum, Washington, DC. http://www.nhpf.org/library/thebasics/Basics_OlderAmericansAct_02-23-12.pdf. Accessed 27 Feb 2019

Older Americans Act (OAA) (1965) Public Law 89-73, 79 Stat. 218, H.R. 3078, Enacted14 Jul 1965. https://www.govinfo.gov/content/pkg/STATUTE-79/pdf/STATUTE-79-Pg21 8.pdf. Accessed 01 Nov 2018

Older Americans Act (OAA) (2008) Amended public law 89-73 [As amended through P.L. 110-246], Enacted 22 May 2008. https://fns- 
F. Perkins, A. Klimczuk, Area Agencies on Aging, [in:] D. Gu, M.E. Dupre (eds.), Encyclopedia of Gerontology and Population Aging, Springer, Cham 2020, pp. 1-5, https://doi.org/10.1007/978-3-31969892-2 219-1.

prod.azureedge.net/sites/default/files/OAA65.pdf. Accessed 01 Nov 2018

Older Americans Act (OAA) (20 16), Amended Public Law 114-144, Enacted 19 Apr 2016. https://legcounsel.house.gov/Comps/Older\%20Americans\%20Act\% 200f\%201965.pdf. Accessed01 Nov 2018

Ortman JM, Velkoff VA, Hogan H (2014) An aging nation: the older population in the United States. U.S. Census Bureau, Washington, DC.

https://www.census.gov/content/dam/Census/library/publications/2014/demo/p251140.pdf. Accessed 27 Feb 2019

Senior Resources Agency on Aging (2020) Summary of 2018-2021 area plan objectives in priority order. http://seniorresourcesec.org/about-us/area-plan. Accessed 8 Jul 2020

Ujvari K, Fox-Grage W, Houser A (2019) Spotlight: older Americans act. AARP Public Policy Institute, Washington, DC.

https://www.aarp.org/content/dam/aarp/ppi/2019/02/older-americans-act.pdf. Accessed 25 Feb 2019

Vespa J (2019) The U.S. Joins Other Countries with Large Aging Populations. U.S. Census Bureau. 08 Oct 2019. https://www.census.gov/library/stories/2018/03/grayingamerica.html. Accessed 01 May 2020

Yao T (2016) Key changes of the older Americans act reauthorization act of 2016. Bifocal 37(6):120-121.

https://www.americanbar.org/content/dam/aba/publications/bifocal/bifocaljulyaugust2016.pdf. Accessed 01 May 2020 